\title{
Soil Quality Indicators On The World Wide Web
}

Linda Lilburne, Graham Sparling, Louis Schipper, Allan Hewitt, Roger Gibson

Landcare Research, PO Box 69, Lincoln New Zealand

Key words: soil health, DSS, environmental quality

Abstract: New Zealand is highly dependent on its soil resource for continued agricultural production, natural ecosystem health, and ecosystem services. To avoid depleting this resource, we need to be able to identify those soils that are being managed unsustainably. We report on a science program that is developing indicators for monitoring soil quality and incorporating these indicators into decision support software to assist land managers and administrators identify at-risk soils, and provide information for state of the environment reporting. The research comprised (a) identifying those soil measurements that best discriminated changes in soil quality and reducing these through principal component analysis, (b) statistically analysing soil databases for comparative purposes and (c) designing an interactive tool which integrates soil quality expertise with a readily interpretable assessment of the quality of a soil sample.

\section{Introduction}

Indicators and standards to assess soil quality are required for environmental reporting, to assess human and natural impacts on soils, and to identify sustainable land management practices (Doran and Parkin, 1994; Sims et al., 1997). In New Zealand, responsibility for regional soil quality reporting lies with 12 Regional Councils, and responsibility for national state of the environment reporting with the Ministry for the Environment. To achieve consistency in regional and national reporting, a standardised methodology and standards for monitoring and decision making are required. Numerous soil chemical, biological and physical characteristics have been suggested as suitable indicators for assessing soil quality (Garlynd et al., 1994; Harris and Bezdicek, 1994; Jordan et al., 1995; Dorin and Parkin, 1996) and are the subject of on-going discussion. The New Zealand

The original version of this chapter was revised: The copyright line was incorrect. This has been corrected. The Erratum to this chapter is available at DOI: 10.1007/978-0-387-35503-0_29 
Ministry for the Environment has proposed three elementary soil indicators, soil organic matter, compaction and acidity, for environmental reporting at regional and national levels. However, the Ministry has not defined desirable target values, ranges or minimum acceptable values for each of these. To interpret the results of monitoring, agencies need to know the natural ranges of the soil quality indicators in New Zealand soils, and when a soil falls outside the expected range. However, New Zealand has diverse soils and multiple land uses (Molloy, 1988) and it is not feasible to define a single national standard that is applicable to all soils and land uses. There is therefore a demand for a readily accessible, cost effective system that allows users to assess soil quality by providing information on means and ranges of soil quality characteristics applicable to the different soils in the users' region.

This paper describes the computer system we are developing and the research underpinning it. This research includes testing of a minimum dataset (MDS) of indicators that can be used to monitor soil quality, analysing soil databases for critical limits in these indicators, and developing an effective way of representing the indicators in terms of soil quality. This quantitative information is combined with qualitative expertise on soil degradation, in a web-based software system.

\section{Developing a minimum dataset of indicators}

Indicators were selected to provide information on the chemical, physical and biological condition of soils in N.Z. (Table 1). The soil indicators chosen are similar to those proposed by overseas researchers (Larson and Pierce, 1994; Doran and Parkin, 1996). From this dataset it is also possible to derive further indicators, such as base saturation, readily available water, total available water, macroporosity, microbial quotient and respiratory quotient, that have also been suggested as useful for soil quality monitoring (Doran and Parkin, 1994; Larson and Pierce, 1994; Garlyn et al., 1994; Harris and Bezdicek, 1994; Jordan et al., 1995).

The minimum dataset was trialled on a range of 80 different sites comprising six major land use classes (indigenous forest, tussock grassland, pasture, plantation forest, arable cropping and market gardening), covering nine soil types. The sensitivity of the various indicators to land use effects was established by examining contrasting land uses on matched sites on the same soil type (Schipper and Sparling, 2000).

We have retained all the original indicators within the MDS with the exception of near and saturated hydraulic conductivity, because all the proposed indicators were responsive to land use and showed differences between soil types. In general, biological indicators showed a greater degree of change than chemical and physical indicators. Hydraulic conductivity 
was dropped from the MDS because the high variability (CV of 48\%) suggests, on average, that we would need 147 samples from each site to be confident of detecting a 10\% change in the mean value (Doran and Jones, 1996). Such a sampling intensity was not practical. Furthermore, changes in the mean values of hydraulic conductivity were relatively modest, and in the range of soils tested, none of the differences between matched sites were significant (Schipper and Sparling 2000). There is the potential to reduce the current dataset further, as discussed later.

Table 1. Soil indicators selected for soil quality monitoring

\begin{tabular}{|c|c|}
\hline Indicator & Soil Quality Information \\
\hline & Chemical \\
\hline Total carbon & Organic matter reserves, biological resource. \\
\hline Total nitrogen & Organic nitrogen reserves, organic matter quality. \\
\hline Cation exchange capacity & $\begin{array}{l}\text { Buffering capacity and ability to retain nutrients. } \\
\text { Derived measurements provide the sum of cations } \\
\text { and base saturation. }\end{array}$ \\
\hline Olsen phosphorus & Plant-available phosphate. \\
\hline PH & $\begin{array}{l}\text { Acidity or alkalinity of soil. } \\
\text { Biological }\end{array}$ \\
\hline $\begin{array}{l}\text { Respiration }\left(\mathrm{CO}_{2}\right. \\
\text { production) }\end{array}$ & $\begin{array}{l}\text { Availability of organic matter reserve, microbial } \\
\text { activity. }\end{array}$ \\
\hline Microbial biomass & $\begin{array}{l}\text { Size of microbiological population, rapidly cycling } \\
\text { organic matter and nutrients. }\end{array}$ \\
\hline $\begin{array}{l}\text { Anaerobically mineralisable } \\
\mathbf{N}\end{array}$ & $\begin{array}{l}\text { Potential of the soil to supply plant-available } \\
\text { nitrogen. } \\
\text { Physical }\end{array}$ \\
\hline Bulk density & $\begin{array}{l}\text { Soil compaction, physical environment for roots } \\
\text { and soil organisms. }\end{array}$ \\
\hline Moisture release & $\begin{array}{l}\text { Availability of water and air, retention of water, } \\
\text { drainage properties }\end{array}$ \\
\hline Hydraulic conductivity & Saturated and Near-saturated conductivity \\
\hline Particle size distribution & $\begin{array}{l}\text { Physical environment for roots and soil organisms, } \\
\text { water retention characteristics, potential nutrient } \\
\text { holding capacity. Combined with moisture release } \\
\text { and bulk density to provide estimates of readily } \\
\text { available water, total available water, total } \\
\text { porosity and macroporosity, all important for } \\
\text { plant growth. }\end{array}$ \\
\hline
\end{tabular}

\section{Analysing database information}

Historical data can be used to establish normal ranges and critical limits for these indicators. The New Zealand National Soils Database (NSD) is a repository of soil and related land information held by Landcare Research. Polygon and point data are available. National coverage of polygon data is available at scales of 1:63,840 (see GUILD at http://www.landcare.cri.nz). 
Point data is available in the NSD for soil profiles (to about $1 \mathrm{~m}$ depth) at 1440 locations. Accurate analyses are available for a comprehensive range of chemical, mineralogical and physical, as well as morphological, attributes (in the period 1964 to 1998).

Values for $0-10 \mathrm{~cm}$ soil depth were derived for each suitable site in the NSD. Sites in the NSD are dominated by pastoral land use (pasture $75 \%$, tussock $2 \%$, exotic forestry $1 \%$, native forestry $3 \%$, other native $12 \%$, orchard $2 \%$, and arable cropping $4 \%$ ).

Basic statistics for organic carbon, bulk density, and $\mathrm{pH}$ indicators were derived for all sites, and for sites within soil taxonomic classes and land use classes. Many of the statistical distributions were skewed, so we characterised central tendencies and spread by estimating medians and quartiles (Figure 1).

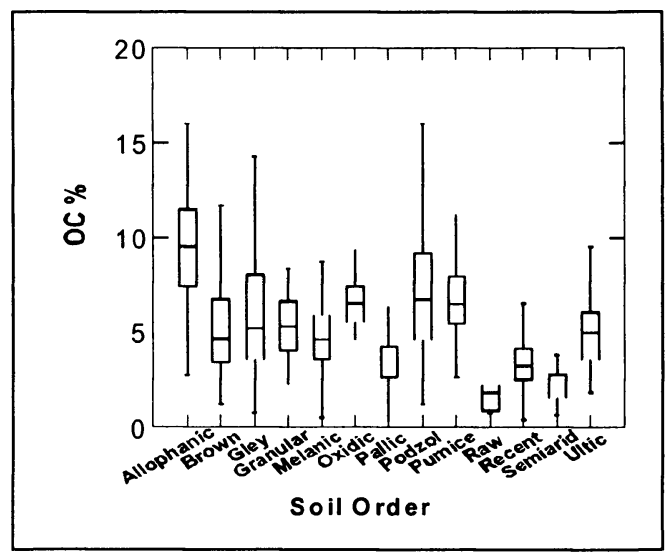

Figure 1. Box-plots of top soil organic carbon \% (OC) for soil orders (Hewitt, 1998) showing medians and upper and lower quartiles

Two standards have been proposed for each indicator: (1) The Environmental bottom line is the limit beyond which soil quality is very poor and critical soil ecosystem functions (including functions that affect productivity) are severely affected. (2) The Level of concern is the limit that signals concern about soil quality.

There is insufficient knowledge yet to propose comprehensive environmental bottom lines. Lower quartiles have been proposed as levels of concern for organic carbon (Hewitt and Sparling 1998). Plots of medians against lower quartiles are shown in Figure 2 where some soil orders are shown to cluster. Suggested levels of concern are specified on the right hand side of the graph for soil orders or clusters of soil orders. 
Many NSD sites lack soil physics data and there is little biological data. Therefore the usefulness of the NSD is limited for some indicators (e.g., macroporosity and anaerobically mineralisable N). However, by using other soil attributes well represented in the database, there is potential to predict values that have not been measured (transfer functions).

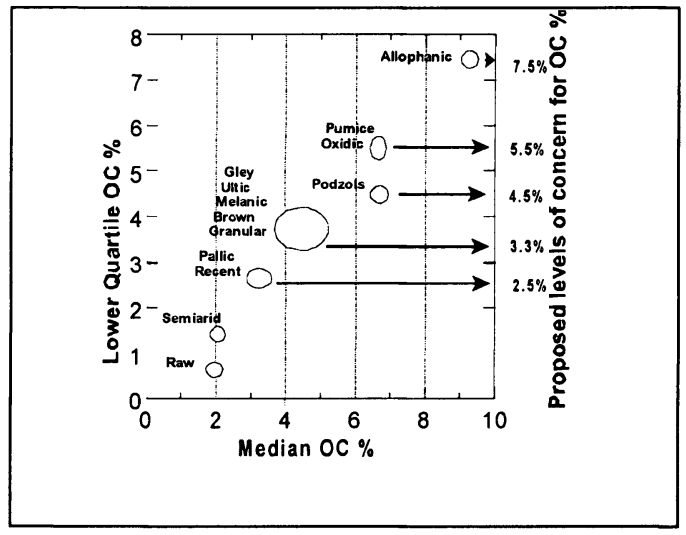

Figure 2. Medians and quartiles of organic carbon (OC) \%

for soil orders from the NSD with proposed levels of concern based on lower quartiles

\section{REPRESENTING SOIL QUALITY USING PRINCIPAL COMPONENTS ANALYSIS}

Trends in soil quality can be difficult to interpret where there are numerous indicators all behaving differently. A single combined index of soil quality would be a useful parameter but we were unable to derive a satisfactory one dimensional index. However, we have investigated the use of multivariate statistics to express soil quality characteristics on a simple two dimensional display. Principal component analysis (PCA) is a multivariate technique which examines the underlying relationships in a large number of variables and determines whether the information can be condensed into a smaller number of factors (or components) (Hair et al. 1995). We found that the information could be reduced to two factors which allows it to be plotted in two dimensions. The output is graphically easy to understand and can also be used to identify outlier sites where soil quality is greater or less than other soils under the same land use. By condensing all the soil quality data to two factors the user is presented with an overall picture of soil quality. While this approach does not directly identify 'good' or 'bad' soil quality, it can highlight sites that have an overall soil condition outside the usual range of other known sites with the same land use. 
Figure 3 is an example plot generated by PCA using our current dataset showing how different land uses group together. Users can select the size of the ellipse, i.e. $80 \%, 90 \% 95 \%$ or $99 \%$ confidence bounds, depending on the level of certainty they wish to use. As our data base grows and the estimates improve, the ellipses should become smaller. In this example, the symbol in the bottom left corner represents a market garden site which shows clear separation from the other arable cropping sites. The separation was caused by the depleted status of the intrinsic resources with very low scores for total $\mathrm{C}$, total $\mathrm{N}$, anaerobic $\mathrm{N}$, microbial biomass $\mathrm{C}$, and microbial respiration, combined with exceptionally high scores for chemical fertility $>($ Olsen $\mathrm{P})$ and greater bulk density. We do not regard any of these trends as desirable, and, although the land is currently being farmed profitably, the soil quality is arguably poor.

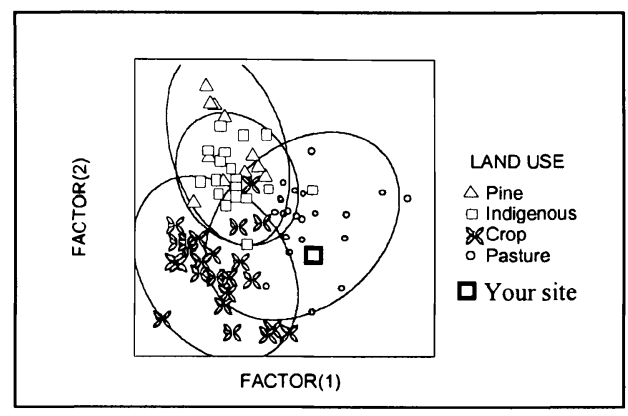

Figure 3. Plots of underlying factors generated from soil quality dataset using principal component analysis, the star designates the user's sample site. Ellipses are $90 \%$ confidence bounds around each land use

Users can compare their own site with other sites by reading the PCA graph. Using equations generated by PCA, the position of a user's site can be calculated and overlaid on the graph. In this example (Figure 3), if the hypothetical sample was collected from a pasture, it fits well with the current database of sites. On the other hand, if the site is actually a pine forest, it is very different from the pine forest sites in the data base.

Our current programme is continually expanding the database. At present we have about 80 sites covering all the land uses which is near the lower number required for PCA if all16 variables in the MDS are used as inputs. It is our target to have 500 examples covering most major soil types and land uses with national coverage. A plot of the loading vectors (Figure 4) shows how the indicators load onto each factor. The longer the vector, the higher the loading. For example, $\mathrm{pH}$ has a high negative loading onto factor 2 but is not significant on factor 1 , hydraulic conductivity (K40) loads lightly onto both factors (negatively on factor 1, positively on factor 2). 
Separation along factor 1 is dominated by soil biological properties (e.g., total carbon, anaerobic nitrogen, microbial biomass carbon), while separation along factor 2 mostly relates to chemical and physical properties (e.g., $\mathrm{pH}$, base saturation, bulk density, readily available water, total porosity). To investigate whether a reduced set of indicators could still provide an adequate characterisation of soil quality, we repeated the multivariate analyses using only six indicators: anaerobically-mineralised $\mathrm{N}$, $\mathrm{pH}$, bulk density, total $\mathrm{C}$, Olsen $\mathrm{P}$, and macroporosity. Although the use of only six indicators adequately distinguished between soil quality under different land uses, we would advise caution in deleting too many indicators from the suggested dataset in Table 1. While some reduction in indicators is clearly possible, there is a need to balance the cost of measuring individual indicators against the value of the information obtained. In our study, the majority of the costs were associated with site identification, description and sampling rather than with the number and range of laboratory analyses. Streamlining the site identification and sampling strategy would be a more effective way of minimising costs rather than reducing the number of analyses.

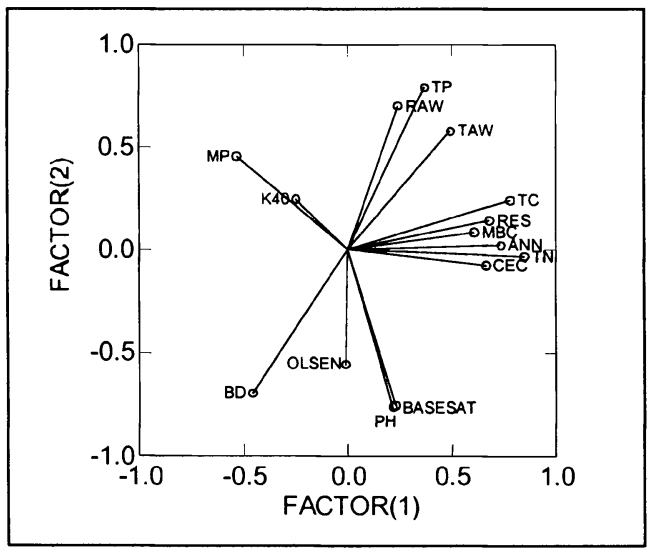

Figure 4. Associated vector plot showing the soil quality indicators that are responsible for the separation between sites 


\section{DESIGN OF THE COMPUTER SYSTEM}

The next stage was to integrate the research described above, i.e., the MDS of indicators, the critical limits obtained from the analysis of the NSD, and the results of the PCA, with qualitative knowledge in a computer system. The aim of the system is to make soil quality expertise accessible to those involved in monitoring soil resources. The system, which is called SINDI (Soil INDIcators), can be used by anyone who has obtained measurements from their sample site(s) of the indicators that make up the minimum dataset. However, it is envisaged that users of SINDI will be those interested in soil quality on a regional or national scale, e.g., regional council staff, rather than on a farm scale. This is because the analyses focus on long term trends over the whole country. The flowchart in Figure 5 represents the sequence of operations the user follows when using SINDI. Dashed arrows represent supporting screens. The user can print the current display or quit the program at any time. The first screen is for data entry. The user inputs the site name, location, region, land use, soil order and values for each indicator that is part of the minimum dataset. Each indicator is described and appropriate limits are set on each input box, preventing entry of invalid data. The user can enter data for either the full set of indicators or the reduced set. A screen of information describing the minimum dataset of indicators can be accessed. The site is then mapped onto the PCA graph which indicates how typical the site is. The user can choose the level of confidence which affects the size of the ellipses. By clicking a button on this screen, the viewer can read an explanation of the PCA graph to help them interpret it. More statistically literate users may wish to view the screen with the loading plot (i.e., Figure 4) which indicates how the indicators are mapped onto the two factors. 


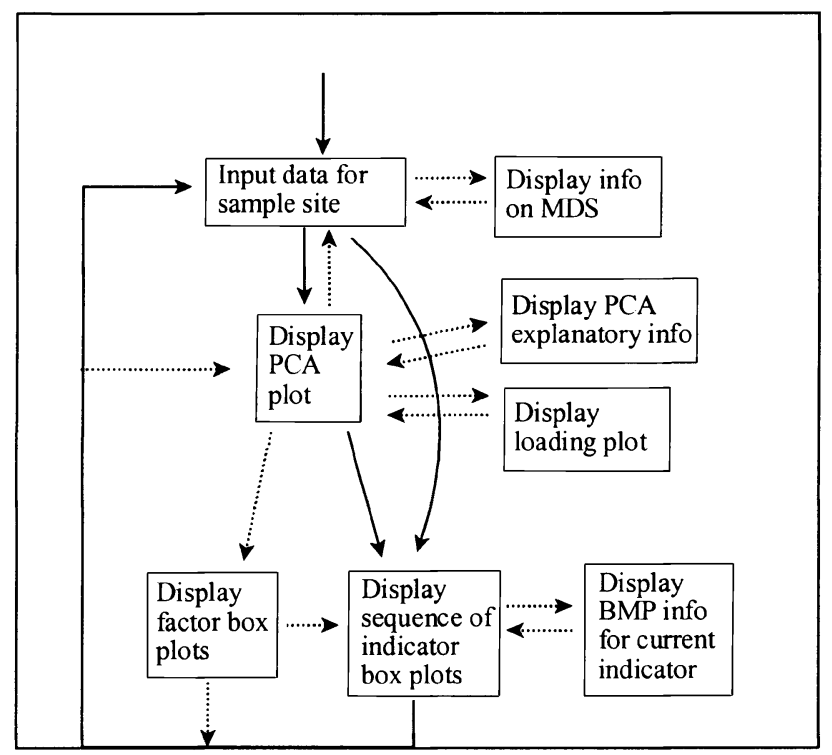

Figure 5. Flowchart showing how SINDI can be used

Further detail on which specific soil indicators are greatly different can be obtained by comparing box plots of individual indicators derived from the NSD (e.g., as in Figure 1). If the soil order is known, and the parameter is a component of the NSD, then means, medians, and upper and lower quartile ranges for that parameter can be provided. For some indicators, such as organic $\mathrm{C}$ content, environmental bottom lines and levels of concern can also be defined. For example, if the site is significantly different on the $\mathrm{x}$ axis (i.e., factor 1), the user could then view a sequence of box plots for total carbon (TC), respiration (RES), microbial biomass (MBC), anaerobically mineralisable $\mathrm{N}(\mathrm{ANN})$, total $\mathrm{N}(\mathrm{TN})$, cation exchange capacity (CEC), bulk density (BD) and macroporosity (MP) to determine which indicator(s) were atypical. By comparing the site indicator with each box plot in the sequence, users can determine which aspect of their soil is different, and whether the difference is of concern. Box plots of each factor can also be displayed.

If insufficient data is supplied to map the site onto a PCA graph, the user may still view box plots for the indicators entered. In particular, the user who enters just the three basic indicators as proposed by the Ministry for the Environment, can view box plots for organic matter, bulk density and $\mathrm{pH}$. While this is useful for just three indicators, examining many box plots can quickly becoming overwhelming without using the PCA graphs to simplify the information. A button on each box plot screen takes the user to a further screen of textual information of possible causes of changes in each indicator and some management guidelines (BMP). 


\section{DISCUSSION}

A working version of SINDI is accessible from htttp://www.landcare.cri.nz/ science/soilquality. Feedback from users will be used to improve the system over the next year. The aim of SINDI is to provide readily accessible information on soil quality. There are two important aspects of accessibility: to condense the knowledge into a readily understood format, and to make the information physically accessible. Thus user-feedback via the website and workshops will be essential to ensure that sufficient explanation is supplied within the system for the various graphs to be readily comprehended. SINDI is a web-based system since most targeted users (i.e., regional and national land administrators and regulators) have access to the world wide web. By using the web, SINDI can be readily accessed from a web-browser without requiring users to obtain and install additional software. Because SINDI is managed centrally, users will always be using the most recent version. As more data are collected and further analyses undertaken, these will be transparently added to SINDI. There are disadvantages in using the web, however. Rapid Application Development (RAD) tools such as Delphi ${ }^{\mathrm{TM}}$ and Visual Basic ${ }^{\mathrm{TM}}$ are very powerful and easy to use in developing an application like SINDI. The first version of SINDI was developed with Delphi 2 and included interactive maps showing locations of all the NSD sites. To web-enable RAD applications, however, involves using Active $\mathrm{X}^{\mathrm{TM}}$ objects which require the user to be running Internet Explorer (or to buy a plug-in for Netscape ${ }^{\mathrm{TM}}$ ) on a Windows (95/NT) system. This would preclude other platforms from running SINDI. To make the maps web-enabled means buying (or writing) additional software, which was beyond our budget. There are also potential performance implications, therefore the design of SINDI currently no longer includes interactive maps. The use of server side graphics avoids security issues and provides reasonable performance by generating all the graphs on the server rather than through the use of client programs.

\section{CONCLUSIONS}

SINDI is a web-based computer system that aims to assist those monitoring soil quality at a regional and national level. Research has been undertaken to determine a useful set of indicators, along with target ranges for each indicator. PCA has proved useful for reducing information provided by the indicators into a graph allowing users to see how their soil site differs from others, thus identifying at-risk soils. The computer system will assist sustainable land management by making soil quality information more widely available and readily accessible. However, to improve environmental performance and to encourage the adoption of more 
sustainable practices will require changes in public perception and attitudes. We see SINDI as part of an information and education package that will assist in this goal.

\section{REFERENCES}

Doran, J. W., and Parkin, T. B. (1994). Defining and Assessing Soil Quality. In "Defining soil quality for a sustainable environment" (J. W. Doran, D. C. Coleman, D. F. Bezdicek and B. A. Stewart, eds.), SSSA Special Publication Number 35., pp. 3-21. Soil Science Society of America, Madison.

Doran, J. W., and Parkin, T. B. (1996). Quantitative indicators of soil quality: A minimum dataset. In "Methods for Assessing Soil Quality" (J. W. Doran and Smith, eds.), SSSA Special Publication No 49, pp. 25-37. Soil Science Society of America, Madison.

Doran, J. W., and Jones, A. J., eds. (1996). Methods for Assessing Soil Quality, Vol. 49, pp.. 1-410. Soil Science Society of America, Madison, Wisconsin, USA.

Garlynd, M. J., Roming, D. E., Harris, R. F., and Kurakov, A. V. (1994). Descriptive and analytical characterization of soil quality/health. In "Defining soil quality for a sustainable environment” (J. W. Doran, D. C. Coleman, D. F. Bezdicek and B. A. Stewart, eds.) SSSA Special Publication Number 35., pp. 159-169. Soil Science Society of America, Madison.

Hair, J. F., Anderson, R. E., Tatham, R. L., and Black, W. C. (1995). Multivariate data analysis. Fourth edition. Prentice Hall.

Harris, R. F., and Bezdicek, D. F. (1994). Descriptive aspects of soil quality/health. In "Defining soil quality for a sustainable environment." (J. W. Doran, D. C. Coleman, D. F. Bezdicek and B. A. Stewart, eds.), Vol. SSSA special publication Number 35., pp. 23-35. Soil Science Society of America, Madison.

Hewitt, A. E. (1998). New Zealand Soil Classification. Landcare Research Science Series No.1, Manaaki Whenua Press.

Hewitt, A. E. and Sparling, G. P. (1998). Setting quality standards for New Zealand soils. Poster to NZ Soil Soc. Conference, Gisborne, Nov. 1998.

Jordan, D., Kremer, R. J., Bergfield, W. A., Kim, K. Y. and Cacnio, V. N. (1995). Evaluation of microbial methods as potential indicators of soil quality in historical agricultural fields. Biology and Fertility of Soils 19, 297-302.

Larson, W. E., and Pierce, F. J. (1994). The dynamics of soil quality as a measure of sustainable management. In "Defining soil quality for a sustainable environment" (J. W. Doran, D. C. Coleman, D. F. Bezdicek and B. A. Stewart, eds.) Vol. SSSA Special Publication Number 35., pp. 37-51. Soil Science Society of America, Madison.

Molloy, L. (1988). Soils in the New Zealand Landscape The living mantle. Mallinson Rendell, Wellington.

Schipper, L. A., and Sparling, G. P. (2000). Performance of a standard set of soil quality indicators over a wide range of soils and land uses. Soil Science Society of America Journal. Accepted.

Sims, J., Cunningham, S., and Sumner, M. (1997). Assessing soil quality for environmental purposes: roles and challenges for soil scientists. J. Environmental Quality. 26, 20-25. 